\title{
ACESSIBILIDADE ESPACIAL EM REFORMAS DE EDIFÍCIOS: DESAFIOS DA ATUAÇÃO PROFISSIONAL
}

\author{
SILVEIRA, Plínio Renan Gonçalves da (1); \\ SANTIAGO, Zilsa Maria Pinto (2)
}

(1) Universidade Federal do Ceará, Mestrando do PPGAU+D

e-mail:pliniorenan@gmail.com

(2)Universidade Federal do Ceará I PPGAU+D, Doutora

e-mail: zilsa@arquitetura.ufc.br

\begin{abstract}
RESUMO
O presente estudo trata das questões práticas, legais e técnicas envolvendo a adaptação de edifícios à legislação e normatização de acessibilidade vigente no Brasil. Tem como objetivo entender e lançar ao debate os principais desafios encontrados por arquitetos na realização destas obras. Ampara-se na pesquisa predominantemente documental de leis e normas referentes à acessibilidade, reformas em edifícios e exercício profissional de Arquitetura, bem como em consultas a arquitetos com experiências nestas adaptações, no sentido de construir reflexões sobre: as principais limitações destas reformas; a responsabilidade técnica; os parâmetros de acessibilidade e suas implicações no espaço, bem como suscitar possíveis encaminhamentos.
\end{abstract}

Palavras chave: acessibilidade; desenho universal; reforma.

\begin{abstract}
This study analyzes the practical, legal and technical issues involved in adaptations of buildings to the legislation and standards of accessibility in effect in Brazil. It aims to understand and debate the main challenges encountered by architects in these works. It is predominantly based on documentary research of laws and norms regarding accessibility, buildings renovations, professional practice of Architecture, and interviews with architects with experiences in these adaptations. The findings from these studies inform the debate on: the main limitations of these renovations; technical responsibility; parameters of accessibility and their implications in space, as well as show possible directions.
\end{abstract}

Keywords: accessibility; universal design; renovation.

\section{INTRODUÇÃO}

A necessidade por mudanças de forma de ocupação e o surgimento de novas tecnologias tornaram crescentes as demandas por reformas nas edificações de uso público, privado ou coletivo no Brasil, sobretudo a partir da década de 1950. Estas reformas são também justificadas devido às novas exigências legais (segurança contra incêndio, planos diretores e códigos de obra dos municípios), aspectos estruturais e de manutenção predial, interesse em valorização patrimonial (trocas de revestimento, pintura, esquadrias, etc. consideradas "obsoletas"), necessidade de racionalização de água e energia (prática geralmente ligada ao 


\section{$\dddot{1}^{\text {eneac }}$}

processo do retrofit), reabilitação de edifícios em áreas com boa mobilidade urbana ou com localização privilegiada para aproveitamento da infraestrutura urbana, entre outros.

Recentemente, sobretudo a partir da homologação do Decreto 5.296/2004, cresce a demanda por reformas de acessibilidade, constituídas de uma série de adaptações visando o atendimento aos parâmetros estabelecidos na legislação e normas técnicas específicas.

Salientamos que para o caso de reformas em acessibilidade, o ordenamento jurídico e as normas técnicas estabelecem padrões menos restritivos, porém, como via de regra estes não foram considerados quando da concepção das edificações, as reformas se apresentam como grandes desafios para profissionais de Arquitetura. Muitos destes prédios antigos possuem limitações técnicas que demandam estudos específicos a fim de garantir o cumprimento das normas e leis, sem comprometer sua funcionalidade e estabilidade. Além destas, existem as limitações de orçamento da obra. Ferreira (2008) aponta que:

O que se verifica na prática é que alguns imóveis antigos, construídos sem qualquer planejamento de acessibilidade, encontrarão maiores dificuldades para a sua adaptação e apresentarão um custo mais elevado na reforma para garantir tal direito. Isto porque o imóvel inicialmente construído com os critérios de acessibilidade tem um custo inferior daquele que necessita sofrer adaptações para garantir a acessibilidade (FERREIRA, 2008).

Verificamos que o desafio em adaptar imóveis existentes está presente desde a etapa de projeto. O "Reabilita", projeto que faz parte do Programa de Tecnologia de Habitação (HABITARE/ FINEP) do Ministério da Ciência e Tecnologia (MCT), analisou os processos de reabilitação de edifícios em áreas centrais de três cidades: São Paulo, Rio de Janeiro e Salvador para fins de Habitação de Interesse Social (HIS). Segundo Croitor (2008, p. 60):

O Projeto Reabilita (2007) identificou uma restrição ao processo de projeto de reabilitação no atendimento às normas vigentes, principalmente no que diz respeito às questões de segurança contra incêndio e acessibilidade. Constatou-se que os projetistas encontram dificuldade em adaptar as condições dos edifícios antigos às demandas de reservação de água para incêndio, devido ao tipo de fundação e às limitações estruturais dos edifícios; à criação de rotas de fuga e escadarias; ao atendimento das exigências de acessibilidade às áreas comuns e à cota de apartamentos prevista por lei em empreendimentos de habitação popular (CROITOR, 2008). ${ }^{1}$

De fato, a criação de rotas de fuga e de rotas acessíveis ${ }^{2}$ prescinde de uma série de requisitos, implicando em adaptações que interferem diretamente na estrutura dos imóveis tais como: alterações no dimensionamento de espaços; ampliação da largura de portas, passagens e corredores a fim de permitir a passagem de pessoas em cadeira de rodas, pessoas obesas, pessoas com muletas, etc; adaptação e/ou construção de escadas; adaptação e/ou construção de rampas; instalação de elevadores ou plataformas; reforma de banheiros - ampliações ou construção de novos banheiros acessíveis, dentre outras adaptações.

\footnotetext{
${ }^{1}$ A Lei Brasileira de Inclusão no 13.146, de 2015 instituiu que 3\% (três por cento) das unidades habitacionais dos programas habitacionais, públicos ou subsidiados com recursos públicos seriam destinados às pessoas com deficiência. Anterior a esta Lei, o Estatuto do Idoso - Lei no 10.741 de 2003 já garantia a reserva de 3\% das unidades habitacionais residenciais para atendimento aos idosos nestes programas (redação dada pela Lei $n^{\circ}$ 12.418, de 2011).

${ }^{2}$ Rotas de fuga são trajetos protegidos para serem percorridos em caso de sinistro. Rotas acessíveis são trajetos contínuos e sem barreiras interligando todos os espaços do edifício, podendo ser utilizados por todas as pessoas, inclusive pessoas com deficiência (ABNT, 2015).
} 
Considerando os entraves encontrados nos casos de reformas, a NBR 9050/2015 apresenta parâmetros específicos como alternativas para estas obras. Para casos extremos, a norma apresenta o conceito da impraticabilidade e o define como "condição ou conjunto de condições físicas ou legais que possam impedir a adaptação de edificações, mobiliário, equipamentos ou elementos à acessibilidade" (ABNT, 2015). É importante frisar, porém que a impraticabilidade deve ser justificada tecnicamente, a fim de garantir que tenham sido esgotadas todas as possibilidades de se obter algum tipo de acessibilidade para determinado quesito.

Em razão das questões apresentadas acima, esta pesquisa objetiva entender o processo de adaptação destes edifícios em seus aspectos técnicos e legais, bem como a partir da visão do projetista. Para tanto, realizamos consultas a vinte arquitetos de cidades diversas do Brasil com experiências nestas adaptações. O foco do trabalho é apresentar e discutir, através da análise destes depoimentos, os principais desafios encontrados por arquitetos na realização destas obras de modo a oferecer subsídios aos profissionais da área em suas atuações profissionais. Deste modo, a pesquisa se faz relevante principalmente para arquitetos e urbanistas, e demais profissionais ligados ao processo de reforma, no sentido de sensibilizá-los em relação às particularidades do tema.

\section{BASE LEGAL PARA ADAPTAÇÕES DE ACESSIBILIDADE}

No Brasil, o movimento político das pessoas com deficiência foi se organizando no final dos anos 1970 e se consolidou na década de 1980 junto aos demais movimentos sociais que lutavam no contexto da abertura política e, posteriormente, da Assembleia Nacional Constituinte a fim de que fossem ouvidas suas reivindicações. A pressão deste movimento resulta num importante começo às condições de acesso das pessoas com deficiência ao espaço construído.

Embora não haja um capítulo específico na Constituição de 1988 voltado às pessoas com deficiência, este e outros direitos foram garantidos e distribuídos ao longo de todos os capítulos da Lei. O Art. $227 \S 2^{\circ}$ apontou a necessidade de normatização de edificações para que possam atender estas pessoas. Além disso, o Art. 244 trouxe o embrião legal para garantia da adaptação de logradouros e edifícios de uso público (BRASIL, 1988).

Algumas iniciativas surgiram nas décadas de 1990, como o Projeto Cidade para Todos, do Programa de Eliminação de Barreiras Arquitetônicas e Ambientais, criado em 1992, por meio da Coordenadoria Nacional para a Integração de Pessoa Portadora de Deficiência (CORDE). Este projeto apoiou experiências municipais de implantação de projetos de acessibilidade no espaço urbano (SANTIAGO, 2005). Apesar destas ações e dos prelúdios da Constituição, ainda não havia, porém, instrumentos legais que estabelecessem a obrigatoriedade explícita da acessibilidade às edificações e ao meio urbano.

Essa obrigatoriedade, contudo, foi definida com a Lei $n^{0}$ 10.098/2000. Em seu Capítulo IV que trata "Da acessibilidade nos edifícios públicos ou de uso coletivo", a lei determinou que:

Art. 11. A construção, ampliação ou reforma de edifícios públicos ou privados destinados ao uso coletivo deverão ser executadas de modo que sejam ou se tornem acessíveis às pessoas portadoras de deficiência ou com mobilidade reduzida (BRASIL, 2000, grifo dos autores).

A Lei supracitada ganhou força em 2004, com a assinatura do Decreto Federal ํo $5.296 / 2004$, determinando que a acessibilidade deveria ser garantida com base nos parâmetros estabelecidos pelo Decreto, pelas normas da ABNT e por legislações específicas. Desta forma, as normas de acessibilidade da ABNT passaram a ter caráter 


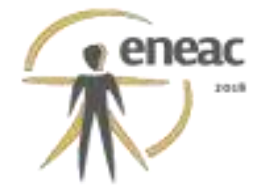

obrigatório, e não apenas recomendatório. O Decreto constitui também um importante marco pelo fato de estabelecer prazos ${ }^{3}$ para que estas adequações fossem realizadas.

Outro passo importante foi a vinculação no Decreto da emissão e renovação dos alvarás de funcionamento e habite-se ao cumprimento da legislação e normas da ABNT:

§ 10 Para concessão de alvará de funcionamento ou sua renovação para qualquer atividade, devem ser observadas e certificadas as regras de acessibilidade previstas neste Decreto e nas normas técnicas de acessibilidade da ABNT.

$\S 20$ Para emissão de carta de "habite-se" ou habilitação equivalente e para sua renovação, quando esta tiver sido emitida anteriormente às exigências de acessibilidade contidas na legislação específica, devem ser observadas e certificadas as regras de acessibilidade previstas neste Decreto e nas normas técnicas de acessibilidade da ABNT (BRASIL, 2004).

O Decreto foi, portanto, um marco regulatório que consolidou, enfim, todos os argumentos legais para garantia de acesso e uso dos espaços para pessoas com deficiência. Mais recentemente, a Lei Brasileira de Inclusão da Pessoa com Deficiência (L.B.I.) no 13.146, de 2015 foi uma conquista que, dentre muitos avanços, atualizou e ampliou a abrangência da legislação de acessibilidade no país, dando resposta a algumas lacunas e colocando o Brasil num patamar privilegiado quanto à questão legal de direitos destas pessoas. Sobre a L.B.I., vale destacar o Artigo 57 que estabelece:

As edificações públicas e privadas de uso coletivo já existentes devem garantir acessibilidade à pessoa com deficiência em todas as suas dependências e serviços, tendo como referência as normas de acessibilidade vigentes (BRASIL, 2015, grifo dos autores).

A partir deste entendimento, destacamos que, num dado edifício com serviços e equipamentos comuns dispostos em mais de um pavimento, não basta que o térreo da edificação seja acessível, ainda que ofereça os mesmos serviços e equipamentos dos demais pavimentos. Vale lembrar que o Decreto 5.296/2004 já garantia em seu Artigo 18 que:

A construção de edificações de uso privado multifamiliar e a construção, ampliação ou reforma de edificações de uso coletivo devem atender aos preceitos da acessibilidade na interligação de todas as partes de uso comum ou abertas ao público, conforme os padrões das normas técnicas de acessibilidade da ABNT (BRASIL, 2004, grifo dos autores).

Sobre este aspecto, de acordo com a NBR 9050/2015:

Para serem considerados acessíveis, todos os espaços, edificações, mobiliários e equipamentos urbanos que vierem a ser projetados, construídos, montados ou implantados, bem como as reformas e ampliações de edificações e equipamentos urbanos, atendem ao disposto nesta Norma (ABNT, 2015).

Expostos os argumentos expressos nas normas e legislações brasileiras, concluímos que todos os espaços de edificações públicas e de uso coletivo, incluindo áreas comuns de empreendimentos residenciais multifamiliares, devem garantir acessibilidade a todas as pessoas. As únicas exceções na lei seriam, portanto, para o caso de áreas privadas, como residências unifamiliares e áreas técnicas de serviço ou de acesso restrito, como casas de máquinas, barriletes, passagem de uso técnico etc. (ABNT, 2015).

\footnotetext{
${ }^{3}$ Foi estabelecido o prazo de 30 meses - a contar da data de publicação - para o caso das adaptações em edifícios públicos existentes, e 48 meses para edifícios de uso coletivo.
} 


\section{(x) $^{\text {reace }}$}

Com base na sólida regulação que foi progressivamente construída no país, diversas ações na justiça passaram a dar ganho de causa para ações que visavam assegurar a acessibilidade às edificações e à cidade. Desta forma, edificações existentes, ainda que antigas e com limitações de diversas ordens, passaram a ser adaptadas em função de novos parâmetros de acessibilidade.

\section{REFORMAS DE EDIFICAÇÕES E RESPONSABILIDADE TÉCNICA}

A NBR 9050/2015 define reforma como "intervenção física em edificação, mobiliário, equipamento urbano ou elemento, que implique a modificação de suas características estruturais e funcionais" (ABNT, 2015). Este processo envolve uma série de atores e etapas numa cadeia complexa de responsabilidades. Cabe destacar que, antes da obra em si, o projeto de reforma deverá passar por análise no órgão licenciador, para receber a licença ou alvará de reforma. Nesta fase o órgão deverá avaliar se o projeto atende aos requisitos técnicos de acessibilidade. De acordo com o § 20 da Lei Brasileira de Inclusão da Pessoa com Deficiência no 13.146/2015:

Para a aprovação, o licenciamento ou a emissão de certificado de projeto executivo arquitetônico, urbanístico e de instalações e equipamentos temporários ou permanentes e para o licenciamento ou a emissão de certificado de conclusão de obra ou de serviço, deve ser atestado o atendimento às regras de acessibilidade (BRASIL, 2015).

O projeto de reforma constitui um documento complexo, exigindo perícia e qualificação do profissional responsável. Isto porque deve responder aos requisitos de um programa de necessidades, atender às normas e legislações e gerenciar os riscos provenientes das alterações estruturais e nos subsistemas da edificação. O processo de projeto pode tornarse consequentemente mais demorado e oneroso. Um aspecto relevante das reformas em edificações diz respeito à responsabilidade técnica. O Decreto 5296/2004 determinou no $\S$ 1ํ do Artigo 11 que:

As entidades de fiscalização profissional das atividades de Engenharia, Arquitetura e correlatas, ao anotarem a responsabilidade técnica dos projetos, exigirão a responsabilidade profissional declarada do atendimento às regras de acessibilidade previstas nas normas técnicas de acessibilidade da ABNT, na legislação específica e neste Decreto (BRASIL, 2004).

Este item foi ratificado pelo Artigo 56 da L.B.I. A cada serviço a ser realizado, os profissionais de Arquitetura, portanto, devem fornecer uma declaração formal por meio do Registro de Responsabilidade Técnica (RRT) no Conselho de Arquitetura e Urbanismo (CAU), sobre o cumprimento da legislação e normas de acessibilidade ou se estas não são aplicáveis, por exemplo, nos casos de reforma em algumas áreas privadas ou de uso restrito.

Além da análise prévia de projeto, após a realização da obra de reforma, o Poder Público Municipal poderá também aferir o cumprimento das regras de acessibilidade quando da concessão ou renovação do alvará de funcionamento, e da emissão da carta de "habite-se" ou habilitação, conforme artigo 60 , parágrafos $1^{\circ}$ e $2^{\circ}$, da L.B.I. e artigo 13 , parágrafos $1^{\circ}$ e 2 do Decreto no 5.296/2004 (CONSELHO NACIONAL DO MINISTÉRIO PÚBLICO, 2016).

Para reformas em espaços de uso público ou coletivo, constatando-se que a legislação e normas de acessibilidade não foram cumpridas, o Ministério Público também poderá ser acionado. Será verificado o projeto, a RRT registrada no CAU (com a declaração sobre o cumprimento das exigências de acessibilidade), podendo ser requisitada, a partir daí, abertura de processo disciplinar no respectivo Conselho. Além disso, poderá ser requisitada lavratura de Inquérito Policial: 
Assim, no caso de existir edificação inacessível, que tenha sido construída ou reformada após o advento do Decreto no 5.296/04, é fundamental que o membro do Ministério Público também verifique a possibilidade de ocorrência de crime pelo profissional da construção civil que declarar de forma falsa a obediência à lei, por ocasião do registro da ART ou da RRT do projeto arquitetônico respectivo. Para isso, é fundamental que sejam requisitadas cópias da ART, junto ao CREA, ou da RRT, junto ao CAU, conforme o caso, e do projeto arquitetônico referente à obra edificada para que se verifique se foi ela projetada erroneamente ou se a construção da edificação é que se deu em desacordo com o projeto original (CONSELHO NACIONAL DO MINISTÉRIO PÚBLICO, 2016).

Uma particularidade a ser destacada é que a Resolução $N^{\circ}$ 51, de 12 de julho de 2013 do CAU estabeleceu o projeto de acessibilidade e ergonomia da edificação como área de atuação privativa de arquitetos e urbanistas. De fato, o arquiteto é o profissional mais indicado para concatenar soluções espaciais em função dos requisitos de acessibilidade, o que não anula a atuação de outros profissionais em reformas desta natureza. Os processos de reforma tornam-se bem sucedidos quando da interação equilibrada entre atores e distribuição das responsabilidades. Algumas soluções apresentadas no projeto arquitetônico, por exemplo, podem envolver complexas alterações estruturais (ou a outros subsistemas da edificação), devendo estar preferencialmente respaldadas por um projeto ou laudo técnico de um engenheiro civil, acompanhados da respectiva ART. A depender do tipo e complexidade das alterações propostas, pode-se necessitar de outros projetos complementares: elétrico, hidráulico, telefonia e lógica, etc.

A partir de 2014, entrou em vigor a Norma Brasileira NBR 16280/2014 (com emenda publicada pela ABNT em 2015): "Reforma em edificações - Sistema de gestão de reformas

- Requisitos". Esta norma apresenta requisitos para a gestão de reformas em áreas comuns e privativas, visando à segurança e sustentabilidade das edificações. A cerca do procedimento de reforma, a NBR 16280/2014 determina:

\begin{abstract}
Apresentação de toda e qualquer modificação que altere ou comprometa a segurança da edificação ou do seu entorno e sistemas comuns da edificação à análise da incorporadora/construtora e do projetista, acompanhada dos devidos documentos de responsabilidades técnicas dentro do prazo decandencial (legal). Após esse prazo, um responsável técnico designado pelo proprietário, ou possuidor ou responsável legal deve efetuar a análise, acompanhada das devidas Anotações ou Registros de Responsabilidade Técnica, observadas as competências profissionais regulamentares (ABNT, 2014b).
\end{abstract}

De acordo com esta norma, a gestão do processo é guiada por um Plano de Reforma elaborado por profissional habilitado, tendo como requisito a apresentação da responsabilidade técnica pelo projeto, pela execução e pela supervisão das obras. Para o caso de reforma em áreas comuns, a norma ratifica a exigência de se cumprir às normas técnicas e legislações vigentes, o que inclui, portanto, as normas e leis de acessibilidade.

A NBR 16.280/2014 define reforma como "alteração nas condições da edificação existente com ou sem mudança de função, visando recuperar, melhorar ou ampliar suas condições de habitabilidade, uso ou segurança, e que não seja manutenção" (ABNT, 2014b). A partir desta definição, podemos afirmar que as adaptações de acessibilidade são reformas visando à melhoria das condições de habitabilidade, de uso e segurança, e possibilitando assim o acesso e uso da edificação por todas as pessoas, inclusive pessoas com deficiência, de forma segura, confortável e autônoma.

Ressaltamos, ainda, que a NBR 15.575/2013 "Edificações Habitacionais - Desempenho" estabelece a "habitabilidade" como requisito de desempenho que advém, dentre outros fatores, da "funcionalidade e acessibilidade". Vale destacar que, embora não se aplique para o caso de reformas, a NBR 15.575/2013 é referenciada como documento indispensável à 




aplicação da NBR 16.280/2014 e tem, portanto, representado um marco referencial também para estes casos.

\section{ADAPTAÇÕES DE ACESSIBILIDADE: QUESTÕES PRÁTICAS}

Através da análise de depoimentos de vinte arquitetos foram prospectadas informações a cerca das experiências com reformas em edifícios de dois ou mais pavimentos, de uso público ou coletivo, incluindo áreas comuns de edifícios residenciais multifamiliares, onde se procurou cumprir os parâmetros de acessibilidade. Quando questionados sobre as principais limitações em se adequar edifícios antigos a estes parâmetros, foram apontadas principalmente as questões dimensionais, estruturais e financeiras.

Foram relatados escassez de mão de obra qualificada para estas intervenções e desconhecimento das normas por grande parte dos projetistas e executores, o que acarreta em recorrentes incompatibilidades com outros projetos e inadequações de execução. ${ }^{4}$ Reforçamos a urgência de que os profissionais da construção civil sejam sensíveis a estas questões, pois mesmo alterações envolvendo poucos centímetros podem ser vitais para o acesso ou uso em determinado ambiente, equipamento ou mobiliário.

Embora algumas questões de acessibilidade sejam passíveis de ser solucionadas apenas com serviços de reparos e instalações tais como: mobiliário acessível, sinalizações diversas (placas em relevo/braile, piso direcional e alerta ${ }^{5}$, mapa tátil, etc.), corrimãos, barras de apoio, entre outros, relatou-se grande dificuldade de encontrar determinados itens de acessibilidade no mercado. Foram citadas, por exemplo, as janelas com dispositivos de fechamento acessíveis, portas que proporcionem vão livre de $80 \mathrm{~cm}$ (uma vez que a porta de largura $80 \mathrm{~cm}$ padrão de mercado não possibilita esta dimensão livre, devido a sua estrutura e batedores), além de cadeiras e poltronas para obesos dentro dos parâmetros da NBR 9050/2015, etc.

Com relação aos parâmetros de acessibilidade, os profissionais apontaram que as maiores dificuldades ocorrem nas adaptações de sanitários, circulação interna, dimensões de ambientes, adaptação ou construção de rampas e adaptação para acesso vertical com elevador ou plataforma. De fato, estes itens representam maior impacto no sentido construtivo, incidem diretamente sobre as limitações dimensionais, estruturais e financeiras destas adaptações e exigem, portanto, maior reconhecimento das técnicas construtivas utilizadas, tais como: tipologia da estrutura, fundações, vedações, cobertas, esquadrias, revestimentos, impermeabilizações, instalações, dentre outros, a fim de se obter subsídios de estudo para as possibilidades de projeto ou impedimentos específicos.

A adaptação de sanitários foi o ponto mais destacado pelos profissionais. Foram relatadas dificuldades de projeto em se encontrar espaços adequados para ampliar ou construir sanitários acessíveis e coletivos (a NBR 9050/2015 também determina parâmetros para estes casos) diante da limitação dimensional de edifícios existentes. A exigência e quantificação de sanitários acessíveis encontram-se no Decreto 5.296/2004, que assim determina:

Art. 22. A construção, ampliação ou reforma de edificações de uso público ou de uso coletivo devem dispor de sanitários acessíveis destinados ao uso por pessoa portadora de deficiência ou com mobilidade reduzida.

\footnotetext{
${ }^{4}$ Foi relatado, por exemplo, o caso em que o espaçamento das lajotas cerâmicas da laje acarretou na mudança do ponto de esgoto e, portanto da locação do vaso acessível, estrangulando o espaço da área de transferência.

${ }^{5}$ Os pisos táteis devem obedecer à norma específica NBR 16537/2016 "Acessibilidade — Sinalização tátil no piso - Diretrizes para elaboração de projetos e instalação".
} 


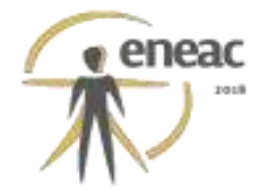

$[\ldots]$

$\S 20$ Nas edificações de uso público já existentes, terão elas prazo de trinta meses a contar da data de publicação deste Decreto para garantir pelo menos um banheiro acessível por pavimento, com entrada independente, distribuindo-se seus equipamentos e acessórios de modo que possam ser utilizados por pessoa portadora de deficiência ou com mobilidade reduzida (BRASIL, 2004, grifo dos autores).

Vale lembrar que o decreto considera edificações existentes aquelas com data de habite-se até o ano de 2004. A partir deste ano, obras de edifícios públicos construídos, ampliados ou reformados devem cumprir a exigência de uma cabine para cada sexo em cada pavimento da edificação, com entrada independente dos sanitários coletivos. Para o caso de edificações de uso coletivo a serem construídas, ampliadas ou reformadas após 2004, o Decreto determina que nos locais onde devam existir banheiros de uso público, os sanitários acessíveis deverão ter entrada independente dos demais. Para o caso das edificações de uso coletivo existentes (ou seja, com habite-se até 2004), no locais onde existem banheiros de uso público, os sanitários acessíveis deverão ter entrada independente, situando-se nos pavimentos acessíveis. Acrescentamos que a NBR 9050/20156 prevê no item 7.4.3.3 que:

Em edificações de uso coletivo a serem ampliadas ou reformadas, com até dois pavimentos e área construída de no máximo $150 \mathrm{~m}^{2}$ por pavimento, as instalações sanitárias acessíveis podem estar localizadas em um único pavimento (ABNT, 2015).

Com relação ao dimensionamento dos sanitários acessíveis, salienta-se que este deve considerar um giro de $360^{\circ}$ da cadeira de rodas, o que implica em um círculo livre de diâmetro $1,50 \mathrm{~m}$ no piso, além das áreas de transferência para a bacia sanitária. Para o caso de reformas, porém, quando não é possível atender às medidas mínimas de sanitário, a norma permite um espaço reduzido, com a possibilidade de giro de $180^{\circ}$ da cadeira de rodas $(1,20 \mathrm{~m} \times 1,50 \mathrm{~m})$, conforme figura abaixo.

Figura 01 - Medidas mínimas de um sanitário acessível em caso de reforma.

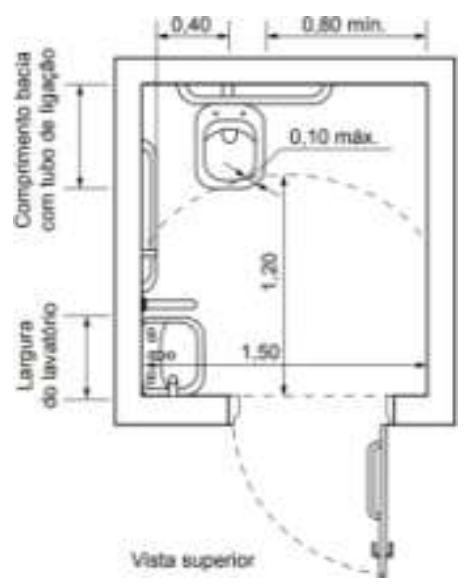

FONTE: ABNT, 2015.

\footnotetext{
${ }^{6}$ A NBR 9050/2015 complementa o Decreto 5.296/2004 na questão da quantificação dos sanitários acessíveis (ver Tabela 06 desta norma), dividindo as edificações pelo tipo de uso (público, coletivo ou privado com áreas de uso comum) e pela situação do imóvel (a ser construído, a ser ampliado ou reformado e existente).
} 


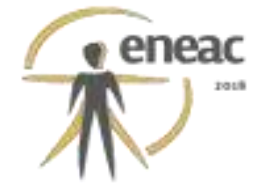

Ainda que tenha área reduzida em caso de reforma, a adição de sanitários acessíveis demanda perícia na avaliação estrutural. Os profissionais relataram também a questão das instalações hidrossanitárias: alimentação das águas frias/ descarte de águas-servidas e da impermeabilização, pois se não observada esta última adequadamente, poderá causar graves patologias com infiltrações e danos à estrutura.

As limitações estruturais dos edifícios também interferem diretamente no redimensionamento de ambientes em função dos parâmetros de circulação, outro ponto destacado pelos arquitetos como de mais difícil adaptação. A ampliação ou abertura de vãos de passagens e portas e o redimensionamento de ambientes demandam alterações na planta do imóvel e exigem ciência do sistema estrutural utilizado. $\mathrm{Na}$ consulta aos profissionais, foi relatado, por exemplo, a impossibilidade de se modificar a planta de edifícios construídos com alvenaria estrutural. A NBR 15961-1/2011 "Alvenaria Estrutural Blocos de concreto. Parte 1: Projeto", responsável por padronizar esta técnica construtiva autoportante, restringe os cortes para este tipo de alvenaria. Cortes horizontais, por exemplo, não podem ser superiores a $40 \mathrm{~cm}$, ou seja, mesmo pequenas adaptações podem tornar-se impraticáveis, a depender do caso.

Em edifícios com estrutura em esqueleto independente (ou seja, composto por fundações, pilares, vigas e lajes solidárias, associadas a fechamentos não estruturais), também se relatou dificuldade de alteração de planta dada a posição dos pilares existentes. A adição de novas alvenarias também é um ponto a ser analisado com diligência para que não haja sobrecarga excessiva. Nestes casos, materiais mais leves como blocos de gesso, blocos concreto celular, drywall, e outros permitem reduzir os impactos na estrutura existente em comparação com blocos cerâmicos, por exemplo.

Em alguns casos, pequenas demolições de elementos de concreto armado precisam ser realizadas para viabilizar as adaptações, porém prescindem de uma avaliação específica. Para estes casos, o Caderno de Especificações Técnicas e de Encargos do Manual de Adaptações de Acessibilidade do Ministério da Justiça e Cidadania/ Secretaria Especial dos Direitos da Pessoa com Deficiência orienta que:

Tais demolições deverão ser realizadas mediante avaliação estrutural e de forma que não apresentem nenhuma interferência na estrutura do prédio. Antecedendo o serviço de demolição deverão ser executados os reforços estruturais e os escoramentos quando necessários (MINISTÉRIO DA JUSTIÇA E CIDADANIA/ SECRETARIA ESPECIAL DOS DIREITOS DA PESSOA COM DEFICIÊNCIA, 2016).

Outro ponto levantado pelos profissionais diz respeito à adaptação ou construção de rampas. Os desníveis nas edificações dificultam ou inviabilizam o acesso principalmente de pessoas em cadeiras de rodas, oferecendo ainda riscos a pessoas com mobilidade reduzida, como idosos, pessoas com muletas, etc. De acordo com o Decreto 5.296/2004:

Art. 20. Na ampliação ou reforma das edificações de uso púbico ou de uso coletivo, os desníveis das áreas de circulação internas ou externas serão transpostos por meio de rampa ou equipamento eletromecânico de deslocamento vertical, quando não for possível outro acesso mais cômodo para pessoa portadora de deficiência ou com mobilidade reduzida, conforme estabelecido nas normas técnicas de acessibilidade da ABNT (BRASIL, 2004).

Para o caso de novas construções, a NBR 9050/2015 determina que as rampas devam ter inclinação máxima de $8,33 \%$, porém em situações excepcionais, ou seja, em reformas onde não há espaço longitudinal suficiente, a norma estabelece a tabela a seguir (Ver Tabela 1), permitindo o dimensionamento de superfícies mais inclinadas com seus limites de desnível e número de segmentos. 


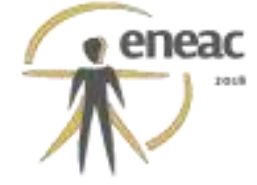

Tabela 01: Dimensionamento de rampas para situações excepcionais

\begin{tabular}{|c|c|c|}
\hline $\begin{array}{c}\text { Desniveis máximos de cada } \\
\text { segmento de rampa } h \\
\mathrm{~m}\end{array}$ & $\begin{array}{c}\text { Inclinação admissivel em } \\
\text { cada segmento de rampa } i \\
\%\end{array}$ & $\begin{array}{c}\text { Número máximo } \\
\text { de segmentos } \\
\text { de rampa }\end{array}$ \\
\hline 0,20 & $8,33(1: 12)<i \leq 10,00(1: 10)$ & 4 \\
\hline 0,075 & $10,00(1: 10)<i \leq 12,5(1: 8)$ & 1 \\
\hline
\end{tabular}

FONTE: ABNT, 2015.

De acordo com a referida tabela, temos que a NBR 9050/2015 permite o desnível máximo de $7,5 \mathrm{~cm}$ a ser vencido com rampa de inclinação máxima de $12,5 \%$, desde que não avance na circulação transversal e seja protegida lateralmente. É importante observar, porém, que não é possível vencer um pavimento fazendo uso destas inclinações especiais, devendo o projetista recorrer à tabela de dimensionamento comum (Tabela 06 da NBR 9050/2015) que permite até 15 lances de rampa de inclinação máxima de 8,33\%, onde cada lance pode vencer até $80 \mathrm{~cm}$, ou seja, permite vencer desníveis de até $12 \mathrm{~m}$, correspondendo a 4 pavimentos.

A construção de novas rampas também deve ser objeto de estudo a fim de dimensionar o acréscimo de carga na estrutura e avaliar se está apta a receber o equipamento. $\mathrm{Na}$ pesquisa, relatou-se que a correção de inclinações de rampas existentes também acarreta acréscimo de carga no edifício. Vale destacar que rampas temporárias, comumente utilizadas como forma de sanar com celeridade o problema, não oferecem acesso igualitário, devendo esta seguir os padrões da ABNT, inclusive com corrimãos, proteções laterais, guias de balizamento e sinalização tátil.

Em caso de impraticabilidade da construção de rampas, deve-se recorrer aos equipamentos eletromecânicos de circulação. Este também foi um item apresentado pelos profissionais como de difícil adaptação, exigindo atenção a cerca da viabilidade técnica. De acordo com NBR 9050/2015: "A circulação vertical pode ser realizada por escadas, rampas ou equipamentos eletromecânicos e é considerada acessível quando atender no mínimo a duas formas de deslocamento vertical". Ou seja, além da escada de acesso aos pavimentos superiores, é preciso que haja outra forma de circulação acessível que pode ser realizada através de equipamentos eletromecânicos de circulação como plataforma de elevação vertical, plataforma de elevação inclinada, elevador vertical ou inclinado, esteiras inclinadas, escadas rolantes com degrau para cadeira de rodas ou através de rampas acessíveis (explanadas nos parágrafos anteriores).

Existem também restrições quanto ao uso destes equipamentos. A plataforma de elevação vertical pode vencer apenas $2 \mathrm{~m}$ caso seja do tipo percurso aberto, ou até $4 \mathrm{~m}$ caso seja do tipo percurso fechado, ou seja, enclausurado em uma caixa. Estas devem ainda obedecer à norma específica ABNT NBR ISO 9386-1. Quanto à plataforma de elevação inclinada, a NBR 9050/2015 determina no item 6.10.4.1 que esta:

[...] pode ser utilizada em reformas de edificações de uso público ou coletivo, quando demonstrada a impraticabilidade de outra forma de acesso, através de laudo técnico por profissional habilitado (ABNT, 2015).

Para maiores deslocamentos verticais, ou seja, em prédios com múltiplos pavimentos, devese, portanto utilizar elevadores convencionais, desde que também atendam à norma específica, neste caso, a NBR NM 313 "Elevadores de passageiros - Requisitos de segurança para construção e instalação - Requisitos particulares para a acessibilidade das pessoas, incluindo pessoas com deficiência". Segundo a NBR 9050/2015, para o caso de reformas em que os poços dos elevadores não tenham as dimensões mínimas exigidos na NBR NM 313, deverá ser prevista outra forma de circulação vertical acessível (ABNT, 2015). 


\section{(x) $^{\text {reace }}$}

O estudo para instalação de equipamentos eletromecânicos de circulação vertical deve considerar a melhor localização de acesso e a viabilidade técnica da proposta. Quando há disponibilidade de espaço no interior da edificação, é possível, em algumas situações, realizar rasgos na laje com abertura de poços. A NBR 6118/2014 "Projeto de estruturas de concreto - Procedimento" preconiza que: "Quando forem previstos furos e aberturas em elementos estruturais, seu efeito na resistência e na deformação deve ser verificado e não podem ser ultrapassados os limites previstos nesta Norma [...]" (ABNT, 2014a). Soluções desta natureza devem ser realizadas através de um projeto específico de reforço estrutural, a fim de que a sobrecarga do elevador e sua estrutura sejam devidamente concordadas com a edificação existente.

Caso seja identificada a impraticabilidade do cumprimento da NBR 6.118/2014, ou seja, a inviabilidade de se abrir poços na estrutura existente, pode-se realizar a construção de um fosso externo contíguo à edificação com estrutura independente e autoportante para receber o elevador ou plataforma, de forma que a abertura das portas seja feita através de rasgos na vedação externa de cada pavimento atendido. Edificações com pátios internos possuem a vantagem de poder receber essa estrutura de forma mais integrada. Ressaltamos que as soluções com torres de estrutura independente, construídas de forma adjacente à edificação existente, também apresentam uma boa alternativa para adição de sanitários, ou caixas de escadas e rampas.

\section{CONSIDERAÇÕES FINAIS}

As reformas em edifícios antigos têm se tornado importantes medidas de sustentabilidade, reabilitando o parque construído no país para os critérios atuais de desempenho. As adaptações de acessibilidade constituem reformas visando melhorar a habitabilidade e requalificar edifícios existentes com relação às exigências de leis e normas de acessibilidade que foram sendo construídas nas últimas décadas, principalmente após a Constituição Federal de 1988 e com maior ênfase com o Decreto n. $\stackrel{0}{5.296 / 2004}$. Para que as adequações sejam exitosas é preciso que os responsáveis legais tenham entendimento das obrigações e que os responsáveis técnicos tenham pleno conhecimento destas regulações.

As reformas são, portanto um caminho para que as edificações antigas sejam utilizadas de forma igualitária, inclusive por pessoas com deficiência. Estas adaptações, porém, exigem conhecimento e habilidade dos projetistas, devendo estes equacionar os parâmetros normativos e legais diante das limitações dimensionais, estruturais e financeiras de grande parte destas edificações. Este exercício torna mais complexo o processo do projeto e exige um reconhecimento de todos os sistemas e subsistemas da edificação a fim de se avaliar a viabilidade técnica das soluções propostas.

$\mathrm{Na}$ pesquisa com arquitetos com experiências em reformas de edifícios com mais de dois pavimentos, de uso público ou coletivo, incluindo áreas comuns de edifícios residenciais multifamiliares, identificamos que as adaptações de sanitários, circulação interna/ dimensões de ambientes, adaptação ou construção de rampas e adaptação para acesso vertical com elevador ou plataforma representam os principais desafios neste processo. Estes desafios suscitam, muitas vezes, soluções alternativas para viabilizar a acessibilidade a estas edificações.

Enfatizamos, porém, que os desafios apontados neste estudo não devem ser compreendidos como objeções às adaptações. Entendemos que tornar uma edificação acessível não é apenas uma necessidade de cumprimento da obrigação legal, mas um dever social para equiparação de direitos. O Desenho Universal e a acessibilidade espacial são ferramentas primordiais na formação de uma sociedade mais inclusiva. 


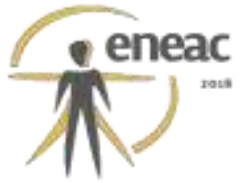

Por fim, concluímos que o projetista possui papel significativo nesta formação. Defendemos o pensar acessibilidade como uma forma de projetar e, que deve induzir esta condição sensível aos demais projetos, como o de paisagismo, de mobilidade urbana e espaços urbanos, de arquitetura de interiores, bem como aos projetos complementares (estrutural, elétrico, hidráulico, lógica, dentre outros).

\section{REFERÊNCIAS BIBLIOGRÁFICAS}

ASSOCIAÇÃO BRASILEIRA DE NORMAS TÉCNICAS. NBR 15961-1. Alvenaria Estrutural - Blocos de concreto. Parte 1: Projeto. ABNT, 2011.

NBR 15575. Edificações Habitacionais — Desempenho. ABNT, 2013.

NBR 6118. Projeto de estruturas de concreto — Procedimento. ABNT, 2014a.

2014b.

NBR 16280. Reforma em edificações - Sistema de gestão de reformas - Requisitos. ABNT,

NBR 9050. Acessibilidade a edificações, mobiliário, espaços e equipamentos urbanos. Rio de janeiro: ABNT, 2015.

BRASIL. Constituição da República Federativa do Brasil de 1988. DF, 1988.

Lei 10.098, de 19 de dezembro de 2000, que estabelece normas gerais e critérios básicos para a promoção da acessibilidade das pessoas portadoras de deficiência ou com mobilidade reduzida, e dá outras providências. Brasília, DF, 2000.

Decreto № 5.296, de 2 de dezembro de 2004, que regulamenta as Leis ํos 10.048 , de 8 de novembro de 2000, e 10.098, de 19 de dezembro de 2000. Brasília, DF, 2004.

Lei Brasileira de Inclusão da Pessoa com Deficiência (Estatuto da Pessoa com Deficiência) no 13.146 de 06 de julho de 2015. Brasília, DF, 2015.

CONSELHO DE ARQUITETURA E URBANISMO DO BRASIL. Resolução $\mathbf{N}^{\circ} \mathbf{5 1}$, de $\mathbf{1 2}$ de julho de 2013. CAU, 2013.

CONSELHO NACIONAL DO MINISTÉRIO PÚBLICO. Guia de atuação do Ministério Público: pessoa com deficiência: direito à acessibilidade, ao atendimento prioritário, ao concurso público, à educação inclusiva, à saúde, à tomada de decisão apoiada e à curatela. Brasília, 2016.

CROITOR, Eduardo Pessoa Nocetti. A gestão de projetos aplicada à reabilitação de edifícios: estudo da interface entre projeto e obra. Dissertação de Mestrado - Escola Politécnica da Universidade de São Paulo. São Paulo, 2008.

FERREIRA, Luiz Antônio Miguel. Acessibilidade em imóveis: questionamentos. 2008. Disponível em <http://www.revistajustitia.com.br/artigos/8wyzdd.pdf>. Acesso em: 10 nov. 2017.

MINISTÉRIO DA JUSTIÇA E CIDADANIA/ SECRETARIA ESPECIAL DOS DIREITOS DA PESSOA COM DEFICIÊNCIA. Manual de Adaptações de Acessibilidade, contendo o laudo padrão e a cesta padrão - ANEXO V Caderno de Especificações Técnicas e de Encargos. Brasília, 2016.

SANTIAGO, Zilsa Maria Pinto. Acessibilidade física no ambiente construído: o caso das escolas municipais de ensino fundamental de Fortaleza - CE (1990 - 2003). Dissertação de Mestrado FAUUSP. São Paulo, 2005. 